\title{
New virtual tool for accurate evaluation of facial volume ${ }^{1}$
}

Rodrigo de Faria Valle Dornelles', Nivaldo Alonso"

'Master, Division of Plastic Surgery, and Fellow PhD degree, Postgraduate Program in Science, Universidade de São Paulo (USP), Brazil. Conception, design, intellectual and scientific content of the study; acquisition, interpretation and analysis of data; manuscript writing.

"PhD, Affiliate Professor, Department of Plastic Surgery, USP, Sao Paulo-SP, Brazil. Conception of the study, critical revision.

\section{- Introduction}

The objective assessment of patients is fundamental both in the preoperative stage regarding planning and postoperative evolution for following up surgical results. Anthropometric measurements may be conventionally obtained through direct measurement, photography or radiography. Volumetric calculation of soft tissues may be obtained through computed tomography (CT) scanning, magnetic resonance imaging (MRI) and ultrasound (US). However, ionizing radiation present in $\mathrm{CT}$, horizontal positioning as a requirement in $\mathrm{MRI}$, non-portability in both, and the need for technical interpretation of US images are factors that make these methods unfeasible in a routine, repeated basis, besides their entailing costs.

The use of three-dimensional (3D) imaging in plastic surgery enables the acquisition of objective data and facilitates preand postoperative evaluation of malformations, trauma and tumor sequelae, and orthognathic surgeries. In addition, 3D imaging facilitates production of virtual planning guides and 3D printing ${ }^{1-6}$, quantification of aesthetic postoperative results ${ }^{7-10}$, and simulation of volumetric changes ${ }^{11-17}$.

Similarly to two-dimensional digital photography files (JPEG, TIFF, PNG), 3D imaging has its digital file format, among them STL (standard tessellation language), appropriate to printing, and OBJ that yields two-dimensional data, as well as texturing of objects. These file formats are mathematical representations of 3D surfaces from inanimate or alive objects, representing polygonal meshes, also named 3D digital meshes or 3D models, and are spatial graphic representations of objects. Such digital files are easily transferable permitting their dispatch for remote evaluation purposes.

Measurements from 3D images are obtained through data extrapolation using specialized software programs integrated into imaging capturing devices, named native or dedicated CAD (computer-aided design) file modelling and analysis software. By purchasing 3D imaging capturing devices, commonly 
known as scanners, users may also acquire their native software programs that enable the extraction of metric information from coordinate data ${ }^{18-20}$. Some of these native software programs enable the calculation of linear, angular, area and volume dimensions and allow comparative analyses. However, the high cost of such devices remains as a limiting factor to the large-scale use of this technology ${ }^{21-23}$. Additionally, all metric-bound studies become inaccessible to the potential users unable to purchase these devices, preventing the exchange of experience, information and consolidation of methods.

Currently, 3D digital meshes are not exclusively provided by scanners, stereophotogrammetry through conventional photography enables the creation of 3D digital meshes with acceptable quantity of polygons for metric calculation, as well as precise data extraction. Furthermore, novel tools and scanners that allow 3D mesh capturing (Structure Sensor, Occipital Inc., San Francisco, CA, USA, Kinect, Microsoft, Redmond, WA, USA) are available on the market ${ }^{24}$. With the evolution of the technology to capture and obtain 3D digital meshes, reduction in device cost is likely to occur or even alternative applications designed for smartphones. Nonetheless, not all companies will provide software for mathematical data extraction or 3D digital mesh measurement.

A free software program is currently available and is being used in medicine to evaluate data extracted from 3D digital meshes (Blender, Blender Foundation, Amsterdam, Netherlands) $)^{19,20,25,26}$ that allow users to capture 3D digital meshes and import their files, providing an array of digital file formats and sources. Although this software is accessible to physicians familiarized with digital technology and may reduce process costs, available information regarding its use to plan facial asymmetry reconstructive procedures remains limited.

Facial digitalization to produce 3D digital meshes creates an exact mathematical representation of real dimensions. Placement of a geometric solid in 3D virtual scene, a cube with known volume in this study, is believed to serve as parameter to accurately evaluate volume in specific regions of the face.

The aim of the present study is to describe a protocol using virtual tools to accurately measure specific facial volumes in cadavers using free software.

\section{Methods}

\section{Specimens and procedures}

This study was evaluated and approved by the Research Ethics Committee, Universidade de São Paulo (research protocol number 001/15).

Eighteen hemifaces from 9 fresh cadavers (5 male, 4 female; age range: 18-78 years) from the Death Verification Service of São Paulo City at the University of São Paulo were included in this study. Specimens with beard or scars were excluded.

Every cadaver was placed on a dissection table in horizontal supine position with its face isolated by surgical field and was attributed a study number. Colored pins were applied to the following cephalometric landmarks: glabella, nasion, mentum, external ocular canthal ligament, and internal ocular canthal ligament. These landmarks were used to align 3D digital meshes. Through a $2-\mathrm{cm}$ intraoral incision in the superior gingival sulcus (Caldwell-Luc procedure), a $4 \times 3-\mathrm{cm}$ dissection was performed in the pre-maxillary region and an empty $16-\mathrm{mL}$ rectangular-shaped tissue 
expander (Silimed, Rio de Janeiro, RJ, Brazil) was introduced into the middle-third of the face, positioning the catheter external valve through the labial commissure.

All 3D digital meshes were captured using a structured-light 3D scanner (Artec 3D MHT, Artec 3D, Luxembourg), at a 70-cm distance from the face, connected to a laptop (Precision M 4700, Dell, Round Rock, TX, USA) through USB cables. The scanner was moved from one side of the face in 180-degree angle surrounding mode up to the contralateral side. Subsequently, saline solution was progressively injected into a tissue expander through its remote valve at three different time points. A 3D digital mesh was captured after the conclusion of every saline solution injecting step totaling 4 digital meshes at 0, 3, 6 and 10 $\mathrm{mL}$ (Figures 1 to 4 ) obtained from every face side. The tissue expander was deflated and the procedure was repeated in the contralateral side of the cadaveric face.

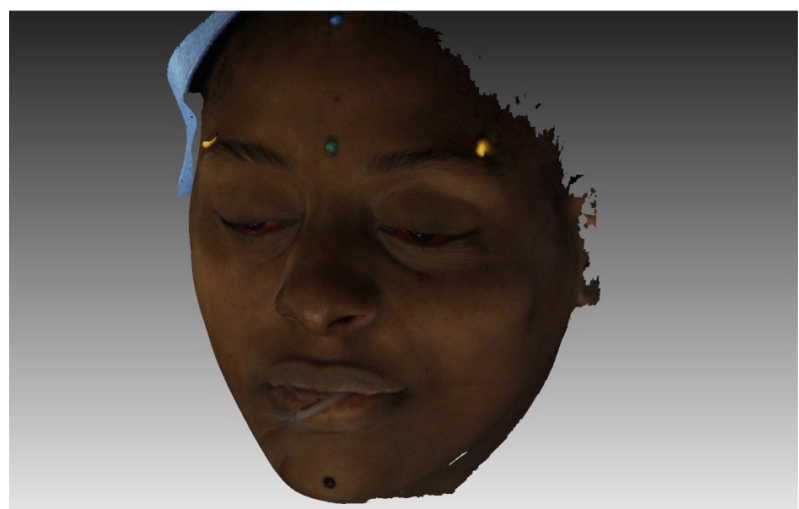

Figure 1 - Left oblique view of 3D digital mesh from cadaveric face obtained using 3D surface scanner with skin texture adjustment after tissue expander was inserted into the left maxillary region. Colored pins and insufflation catheter through oral commissure are shown. Tissue expander volume: $0 \mathrm{~mL}$

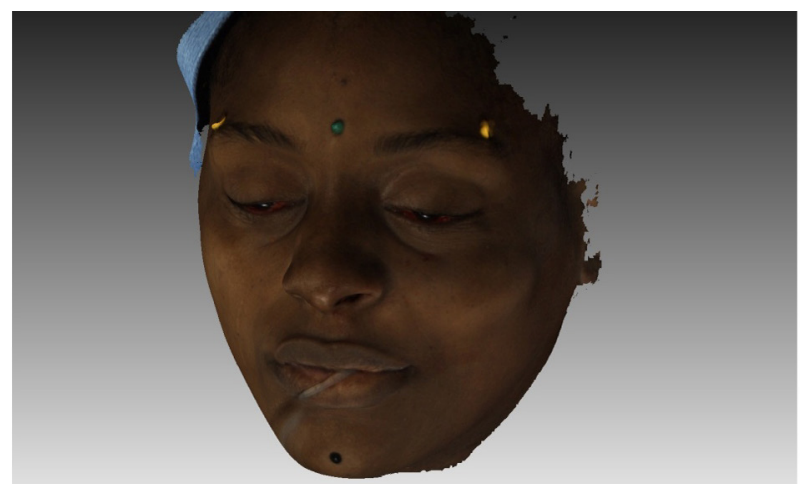

Figure 2 - Left oblique view of 3D mesh from cadaveric face obtained using 3D surface scanner with skin texture adjustment after tissue expander was inserted into the left maxillary region. Colored pins and insufflation catheter through oral commissure are shown. Tissue expander volume: $3 \mathrm{~mL}$.

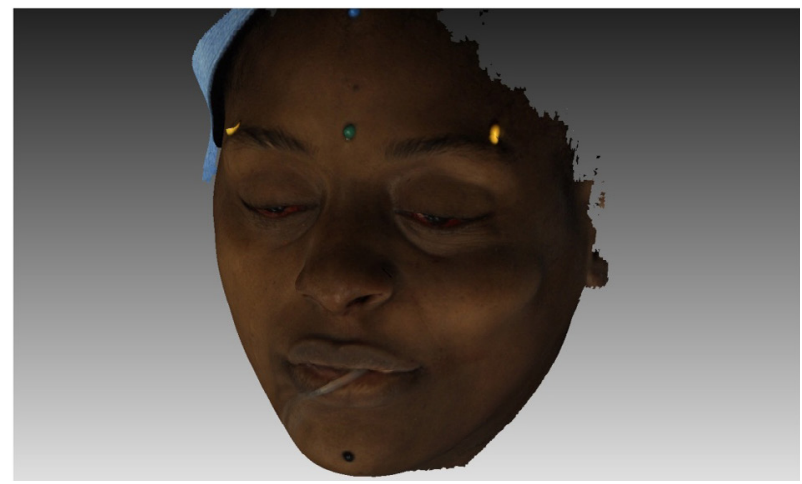

Figure 3 - Left oblique view of 3D mesh from cadaveric face obtained using 3D surface scanner with skin texture adjustment after tissue expander was inserted into the left maxillary region. Colored pins and insufflation catheter through oral commissure are shown. Tissue expander volume: $6 \mathrm{~mL}$.

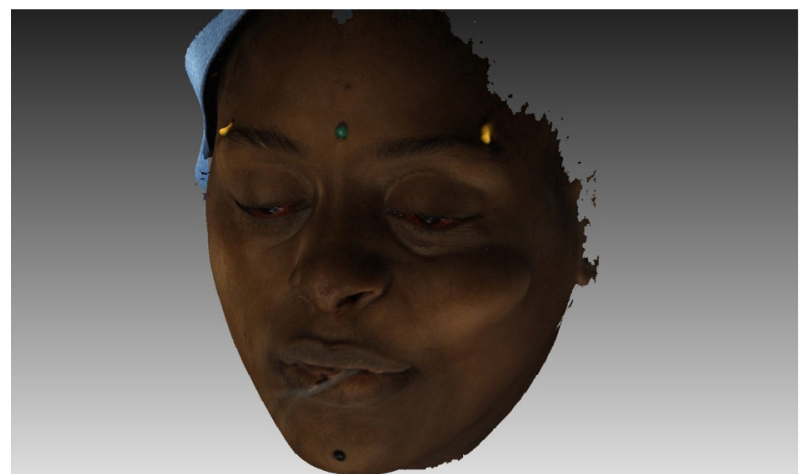

Figure 4 - Left oblique view of 3D mesh from cadaveric face obtained using 3D surface scanner with skin texture adjustment after tissue expander inserted into the left maxillary region. Colored pins and insufflation catheter through oral commissure are shown. Tissue expander volume: $10 \mathrm{~mL}$. 
All 3D digital images captured were reconstructed using software native to the scanning device (Artec Studio 9, Artec 3D). Resulting 3D digital meshes were saved as OBJ files in separate folders. These files were imported by 3D data software (Blender, V2.76, Blender Foundation) through a script (instruction set for function execution in a determined application) in Python programming language (Python Software Foundation, Wilmington, DE, USA) created at CTI Renato Archer (Information Technology Center in Campinas, SP, Brazil). (Figure 5)

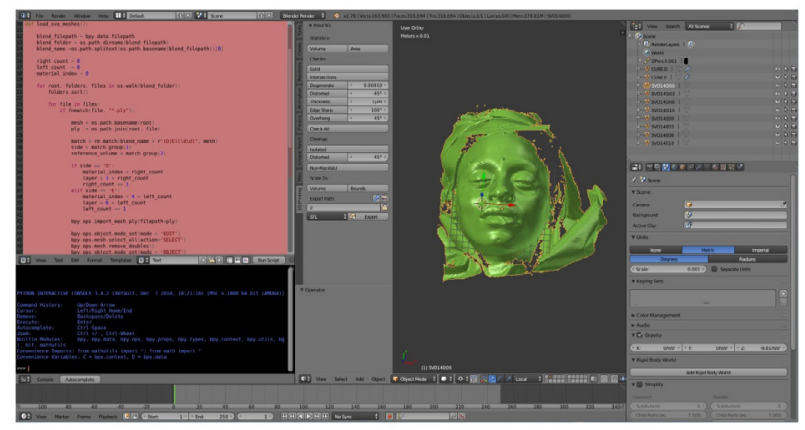

Figure 5 - Blender print screen displaying a 3D facial digital mesh in green inside the 3D view scene window on the right and its import mesh script at the pink upper left window.

After importing files, a metric unit system was adjusted in scene at a 0.001-scale with Blender Misc and 3D printing add-ons activated. All 3D digital facial meshes with insufflated tissue expanders were aligned against a reference mesh created with an empty expander for every cadaveric face side evaluated, using cephalometric landmarks marked with pins as reference. Two virtual cubes with known volume $(7 \times 7 \times 7 \mathrm{~cm}$ - total volume: $343 \mathrm{~cm}^{3}$ ) were added to the $3 \mathrm{D}$ scene. Every cube was manually positioned to include the maxillary area with a cube symmetrically intersecting the contralateral side without expander. The exact space positioning of cubes was replicated in every one of the 3D meshes in different layers using Blender. By applying a Boolean modifier (method of combining or subtracting solid objects among each other to create a new shape), every cube was submitted to a command of difference in relation to its corresponding mesh creating a cut cube in its interface with the mesh. Volume of the external portion for every cut cube was calculated using 3D printing add-on (Figures 6 to 9). Every measurement was performed three times at different time points. The difference between an initial and final volume value for every virtual cube external section in relation to the mesh with an empty expander was calculated.

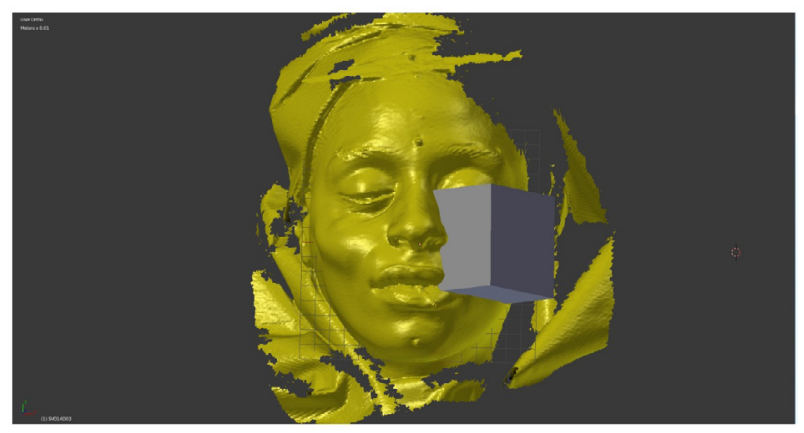

Figure 6 - Positioning of a virtual cube into the left facial side to be intersected and have its volume measured.

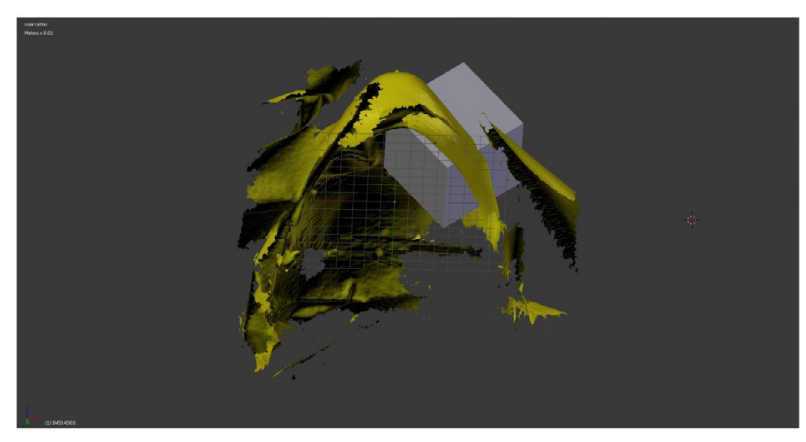

Figure 7 - Inferior view of a virtual cube intersecting a facial mesh. 


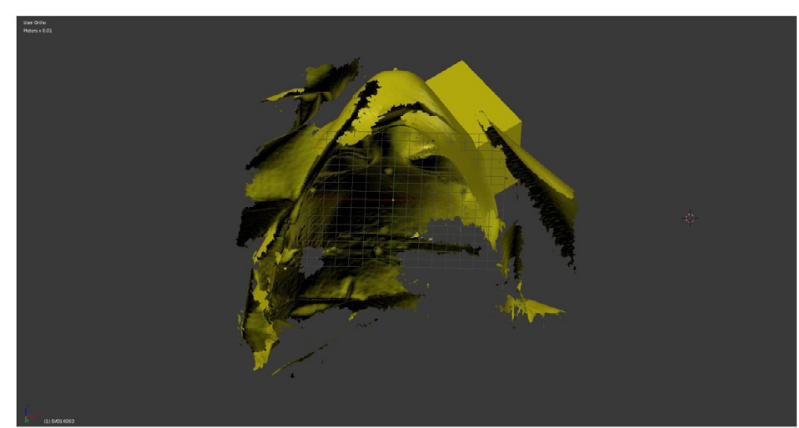

Figure 8 - Inferior view of intersected virtual cube after subtraction by facial mesh surface.

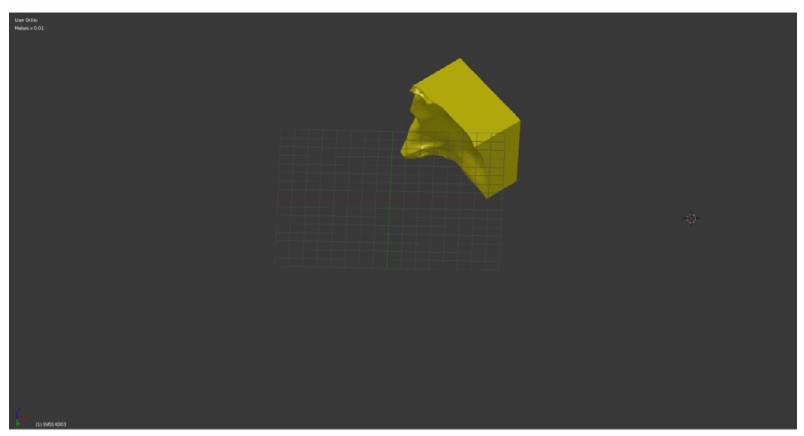

Figure 9 - Virtual cube external section isolated after intersection and ready to proceed to the volumetric calculation phase.

An index, conventionally named Accurate Volumetric Index (AVI), was created to define the difference of volume between every external section of a measured virtual cube subtracted from the external section of the virtual cube 3D digital mesh from the face side of reference. By convention AVI equals -1 whenever the measured volume is higher than the reference volume, $\mathrm{AVI}$ equals 0 whenever no difference between measured volumes is verified, and $A V I$ equals +1 whenever the external section of measured virtual cube is lower than the external section of the reference virtual cube.

\section{Data analysis}

Sample calculation analysis suggested that the correlations between observed volumetric measurements would present values greater than 0.80 . For tests with power at $80 \%$ and significance level at $5 \%$, nine samples would be required.

All data were tabulated using electronic spreadsheet software (Excel, Microsoft, Redmond, WA, USA). Data analysis was performed using statistical software (SPSS 17.0 for Windows). Quantitative variables were described by observing minimum and maximum values and calculating means, standard deviations and quartiles. Data from control tissue expander sides were compared using nonparametric WilcoxonSigned Rank classification test. As for the study of correlations, Pearson-product moment correlation coefficient was applied. Statistical significance level at $\mathrm{P}<0.05$ was used to conduct this study.

\section{- Results}

Mean volume difference between virtual cube external sections compared to the virtual cube external section of reference for every face side at every expansion time point was calculated. Volumetric measurement of the virtual cube external section related to the 3D facial mesh revealed variation between minimum and maximum values for every insufflation step of every face side. Reduction in volume means for virtual cube external sections was verified in relation to reference measurement (0-mL expansion). Standard deviation derived from minimum and maximum measurements with approximate values was found to yield reduction as well (Table 1). 
Table 1 - Descriptive values for volumetric relationship between tissue expander and virtual cube external section*.

\begin{tabular}{llllll}
\hline Side & $\begin{array}{l}\text { Tissue Expander } \\
\text { Volume }(\mathbf{m L})\end{array}$ & $\begin{array}{l}\text { Virtual Cube External } \\
\text { Section }\left(\mathbf{c m}^{3}\right)\end{array}$ & $\begin{array}{l}\text { Mean } \\
\left(\mathbf{c m}^{3}\right)\end{array}$ & $\begin{array}{l}\text { Minimum } \\
\left(\mathbf{c m}^{3}\right)\end{array}$ & $\begin{array}{l}\text { Maximum } \\
\left(\mathbf{c m}^{3}\right)\end{array}$ \\
\hline RIGHT & 0 & 162.8 & $(26.8)$ & 118 & 201.1 \\
& 3 & 158.9 & $(26.7)$ & 113.2 & 197.5 \\
& 6 & 154.4 & $(26.6)$ & 108 & 191.9 \\
& 10 & 147.1 & $(26.1)$ & 102.1 & 184 \\
LEFT & 0 & 151.3 & $(31.3)$ & 105 & 192.2 \\
& 3 & 146.7 & $(31.4)$ & 101 & 188.5 \\
& 6 & 142.1 & $(31.7)$ & 95.7 & 184.4 \\
& 10 & 135.8 & $(32.3)$ & 86.6 & 179 \\
\hline
\end{tabular}

${ }^{*} \mathrm{~N}=9$ for all measurements. Data reported as standard deviation and (minimum, maximum) extension for the external part in relation to virtual cube digital mesh.

A strong correlation was observed between all measurements (Table 2). Linear correlation plots were found to have a uniform positive linear increase for volume differences of virtual cube external sections related to the reference virtual cube external section in the 18 hemifaces studied (Figure $10 \mathrm{~A}-\mathrm{B}$ ). Measurements were simultaneously taken from the contralateral side without tissue expander. All face sides not expanded were found to have delta significantly lower across measured virtual cube external sections compared to virtual cube external sections of face sides with expander $(P=0.008)$ (Table 3). AVI was found to be -1 on the face side without expander and +1 on the side with expander in all cases. No AVI values equaling 0 were observed in this study.

Table 2 - Correlation between volumetric measurement differences from virtual cube external section of expanded 3D hemifaces compared to the virtual cube external section from 3D face side of reference (with empty tissue expander) vs. tissue expander stages*.

\begin{tabular}{lllll} 
Side & \multicolumn{3}{l}{ Tissue Expander Volume } \\
& & $3 \mathrm{~mL}$ & $\mathbf{6 ~ m L}$ & $10 \mathrm{~mL}$ \\
\hline Right & $r$ & 1.000 & 0.998 & 0.997 \\
& $P<$ & .001 & .001 & .001 \\
Left & $r$ & 1.000 & 0.999 & 0.998 \\
& $P<$ & .001 & .001 & .001 \\
\hline
\end{tabular}

*Data reported as Pearson Correlation Coefficient ( $r)$. 

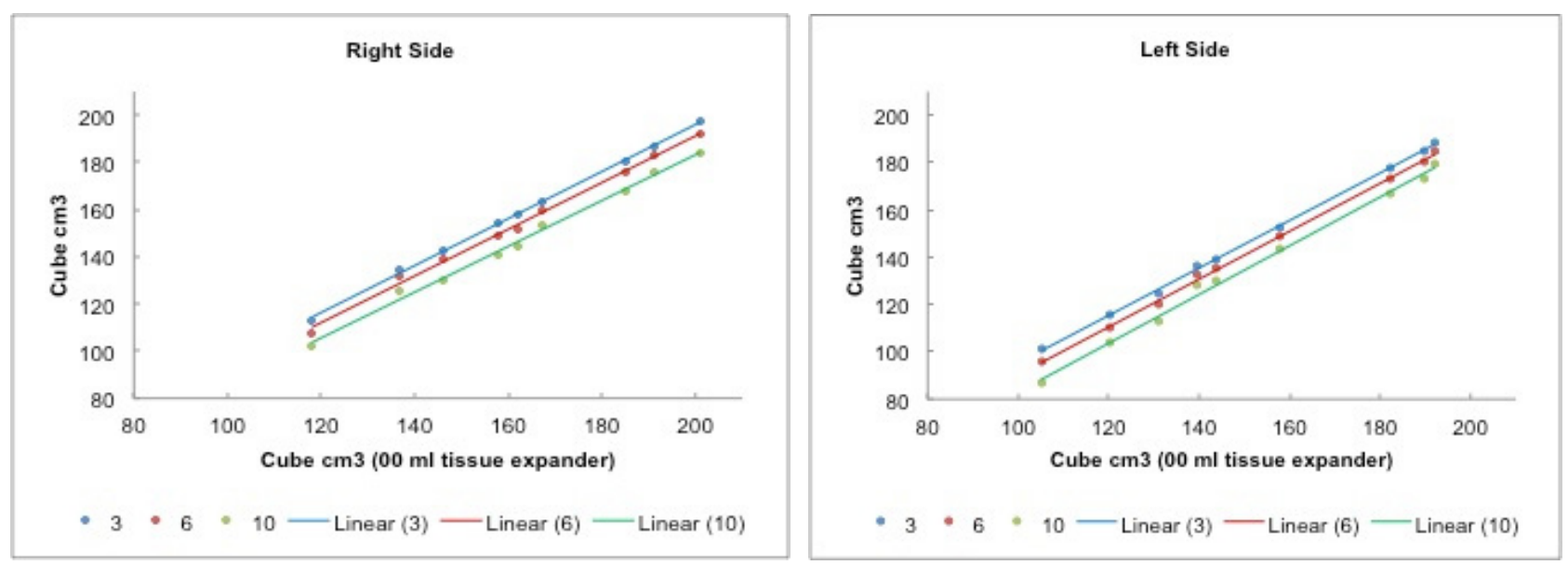

Figure 10 - Linear correlation between expansion stages and reference volume, where horizontal axis corresponds to volume of virtual cube external section $\left(\mathrm{cm}^{3}\right)$, with a $00-\mathrm{mL}$ volume in tissue expander, and vertical axis to volume of virtual cube external section $\left(\mathrm{cm}^{3}\right)$, correlated to volume in tissue expander with 03 $\mathrm{mL}$ (blue), $06 \mathrm{~mL}$ (red) and $10 \mathrm{~mL}$ (green) of saline solution. (A) Right side of the face. (B) Left side of the face.

Table 3 - Descriptive values for volumetric changes in volume difference from virtual cube external sections at every expansion stage compared to the external section volume of reference virtual cube*.

\begin{tabular}{|c|c|c|c|c|c|}
\hline Side & Difference (mL) & Measured Side & $\begin{array}{l}\text { Cube }\left(\mathrm{cm}^{3}\right) \\
\text { Means }\end{array}$ & (SD) & (Minimum, Maximum) \\
\hline \multirow[t]{6}{*}{ Right } & 0 vs. 3 & Expanded & 3.9 & $(0.8)$ & $(2.3,4.9)$ \\
\hline & & Contralateral & -0.1 & $(0.4)$ & $(-0.7,0.5)$ \\
\hline & 0 vs. 6 & Expanded & 8.4 & (1.5) & $(5.2,10.1)$ \\
\hline & & Contralateral & -0.2 & $(0.7)$ & $(-1.3,0.8)$ \\
\hline & 0 vs. 10 & Expandidaed & 15.7 & (2.1) & $(1.1,17.5)$ \\
\hline & & Contralateral & -0.3 & $(0.8)$ & $(-1.6,1.1)$ \\
\hline \multirow[t]{6}{*}{ Left } & 0 vs. 3 & Expanded & 4.5 & $(0.8)$ & $(3.4,6)$ \\
\hline & & Contralateral & -0.2 & $(0.2)$ & $(-0.7,0.03)$ \\
\hline & 0 vs. 6 & Expanded & 9.2 & $(1.2)$ & $(7.1,11.3)$ \\
\hline & & Contralateral & -0.5 & $(0.4)$ & $(-1.3,0.1)$ \\
\hline & 0 vs. 10 & Expanded & 15.5 & $(2.2)$ & $(12,18.4)$ \\
\hline & & Contralateral & -0.7 & $(0.5)$ & $(-1.5,-0.1)$ \\
\hline
\end{tabular}

$\mathrm{N}=9$ for all measurements. Data reported as standard deviation (SD) and (Minimum, Maximum) variation.

The cadaveric faces histogram

variation (Figure 11). analyses demonstrated linear distance 


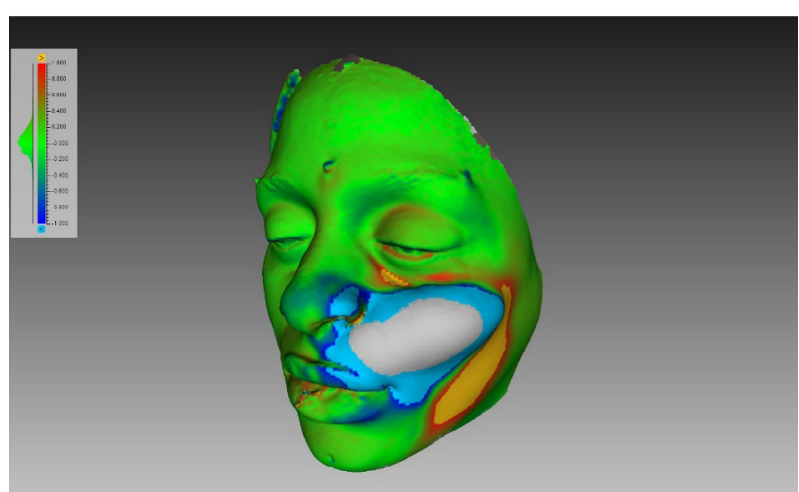

Figure 11 - Oblique view of histogram comparing deviations between 3D digital meshes of a cadaver obtained from 3D surface scanner with no skin texturing. Comparison was performed with tissue expander insufflation from $0 \mathrm{~mL}$ and 10 $\mathrm{mL}$. Linear difference of alignment region on skin surface region into which an expander was placed is displayed by a scale of different colors, where green refers to minimum (approximately $00 \mathrm{~mm}$ ), yellow to negative $(<1 \mathrm{~mm})$ and blue to positive $(>1$ $\mathrm{mm}$ ). Gray refers to extrapolation of the scale, i.e., greater than 1-mm difference.

\section{- Discussion}

Among anthropometric measurements, volume of an anatomic region is important to evaluate, plan and follow up plastic surgery patients. Some software programs provide histogramanalysestomapanydistance between two digital meshes after their alignment limited exclusively to a linear distance variation between every surface without quantifying the volume of this variation ${ }^{11,16,19,27-30}$. The volumetric protocol evaluation used in this study allowed volumetric measurements in 3D digital meshes to be performed in specific facial regions according to the decision taken by the surgeon. The difference between one 3D digital mesh to the other allowed volume calculation in a noninvasive, nonionizing manner.

An experimental model using cadavers was selected because specimens enabled tests with complex 3D digital meshes with a great number of polygons that underwent regional deformation whenever submitted to traction and stretching. Observed AVI variation (side with expander +1 and without expander -1) may not be present in studies with organic tissue and was attributed to tissue adaptive elastic capacity. However, this particularity may be observed in virtual experiments and should be taken into consideration in reconstructive surgical planning ${ }^{31}$. Prior studies conducted with human-form mannequins were found to be unable to provide these variations due to their simpler polygonal composition and static 3D architecture despite structural changes in their proximities ${ }^{32-34}$. Deformities in 3D meshes should be foreseen both at the site to be expanded and around its perimeter indicating tissue behavior under traction or pressure. These deformities have been studied and constitute a further step towards the use of predictive models, such as volume response in virtual simulation of orthognathic surgery ${ }^{31,35}$.

A total sample of 18 hemifaces yielded 72 total facial 3D digital meshes and 144 virtual cube external sections for analysis and were found to present an acceptable correlation between tissue expander volume and virtual cube external section volume during expansion (Table 2).

A portable structured-light 3D scanner that provides complex 3D digital mesh with no need for calibration ${ }^{36}$ was used to confirm the volumetric calculation protocol regardless of the 3D digital mesh source, enabling the use of other capturing forms, such as serial photographs (photogrammetry).

Digital mesh alignment was used with the initial mesh positioned without tissue expander (tissue expander volume at $0 \mathrm{~mL}$ ). In a previous study conducted by the authors, the possibility of calculating in relation to a 2-mesh alignment cut was considered, but a totally virtual process or a free software program was not used to perform calculations ${ }^{37}$. In the present study, the use of virtual tools along all 
the process was found to reduce interference by operators and lead to less interference in the results obtained.

Volume results from virtual cube external section observed during tissue expander expansion were found to present variation related to absolute infiltrated saline solution volume, overlapping at every time point, but a linear relation was maintained. Absolute volume absent in an asymmetric deformity may be an approximate quantifier, although it does not necessarily equal the volume of tissue required for correction because in the correction, for instance, fat graft absorption rate or even soft tissue elastic capacity in tight bone prosthesis adaptation modifies the quantity required for treatment. Measured AVI may have a role in asymmetry treatment programming because it objectively quantifies the correlation and may indicate an individualized absorption pattern with serial analysis as a parameter to correct subsequent surgical procedures.

The 3D technology used in this study has been formerly applied in a variety of medical fields, including plastic surgery ${ }^{10,38-40}$. Many studies using different applications have reported precision and reproducibility ${ }^{41-43}$. Nonetheless, the elevated cost associated to image capturing devices may limit clinical study and its application, making the dissemination of this tool to evaluate, plan and follow up surgeries more difficult. Consequently, data computed resources are linked to equipment purchase ${ }^{44}$. In the present study, technology with low-cost tools was selected by the authors, such as open source software available on the internet, with the benefit of providing permanent worldwide cooperation with constant updates according to the needs of users.

Capturing 3D digital meshes has increasingly become popularized with the launch of less costly scanners and applications for mobile devices or free cloud-based services that allow 3D image capturing at no cost and quickly (Autodesk ${ }^{\circ}$ ReCap 360 'м , Autodesk, San Rafael, CA, USA and Agisoft PhotoScan, Agisoft, Saint Petersburg, Russia). Therefore, maintaining the accessibility to anthropometric measurement processing remains as an important requirement. This accessibility is feasible with free software, a multiplatform used in the present study.

Clinical application may include facial asymmetry evaluation, correction and follow up in plastic surgery patients ${ }^{45}$. Fat grafting may be quantified and planned at low cost and morbidity using $\mathrm{AVI}$ as predictive factor for the volume to be replaced or observed along follow-up evolution. Consequently, studies with MRI or CT, which are costly, present elevated morbidity (CT scanning uses ionizing radiation) may be complemented or replaced by virtual evaluation with 3D digital meshes during evaluation and follow-up stages ${ }^{46}$.

The need for basic technological knowledge on 3D technology, its concepts and tools, as well as a computer with video card adequate to the speed to manipulate 3D images may be considered as limitations to this method. Availability of scanners to capture 3D digital meshes also restricts the use of this method, but the increasing offer of free applications and software programs to create $3 D$ models, as well as the use of stereophotogrammetry from photographs, are promising and may enable this method to become even more accessible.

\section{Conclusions}

Facial volumetric evaluation in cadavers was found to be possible with virtual methods from 3D digital meshes by using a surface scanner in the present study. The method was proved to be efficient to calculate local volumetric variation at low cost due to free open source software. Further studies and training programs are required so that colleagues might be able to exchange information, develop 
indications and increase the availability of this method in reconstructive and plastic surgery.

\section{References}

1. Chen Z-C, Albdour MN, Lizardo JA, Chen Y-A, Chen PK-T. Precision of three-dimensional stereo-photogrammetry $\left(3 \mathrm{dMD}^{\mathrm{TM}}\right)$ in anthropometry of the auricle and its application in microtia reconstruction. J Plast Reconstr Aesthet Surg. 2015;68(5):622-31. doi: 10.1016/j.bjps.2015.02.020.

2. Choi JW, Kim N. Clinical application of three-dimensional printing technology in craniofacial plastic surgery. Arch Plast Surg. 2015 May;42(3):267-77. doi: 10.5999/ aps.2015.42.3.267.

3. Tarsitano A, Del Corso G, Ciocca L, Scotti R, Marchetti C. Mandibular reconstructions using computer-aided design/computeraided manufacturing: A systematic review of a defect-based reconstructive algorithm. J CraniomaxillofacSurg. 2015 Nov;43(9):178591. doi: 10.1016/j.jcms.2015.08.006.

4. Gerstle TL, Ibrahim AM, Kim PS, Lee BT, Lin SJ. A plastic surgery application in evolution: three-dimensional printing. Plast Reconstr Surg. 2014 Feb;133(2):446-51. doi: 10.1097/01.prs.0000436844.92623.d3.

5. Gillis JA, Morris SF. Three-dimensional printing of perforator vascular anatomy. Plast Reconstr Surg. 2014 Jan;133(1):80e-2e. doi: 10.1097/01.prs.0000436802.12423.3f.

6. Lim SH, Kim MK, Kang SH. Precision of fibula positioning guide in mandibular reconstruction with a fibula graft. Head Face Med. 2016;12(1):7. doi: 10.1186/s13005016-0104-2.

7. Chang JB, Small KH, Choi M, Karp N. Three-dimensional surface imaging in plastic surgery: foundation, practical applications, and beyond. Plast Reconstr Surg. 2015;135:1295-304. doi: 10.1097/ PRS.0000000000001221.

8. Nord F, Ferjencik R, Seifert B, Lanzer M, Gander T, Matthews F, Rucker M, Lubbers HT. The 3dMD photogrammetric photo system in cranio-maxillofacial surgery: Validation of interexaminer variations and perceptions. J Craniomaxillofac Surg. 2015 Nov;43(9):1798-803. doi: 10.1016/j. jcms.2015.08.017.
9. Sforza C, Dolci C, Tommasi DG, Pisoni $L$, De Menezes M, Elamin F. Threedimensional facial distances of Northern Sudanese persons from childhood to young adulthood. J Craniomaxillofac Surg. 2014 Jul;42(5):e318-26. doi: 10.1016/j. jcms.2013.10.013.

10.Pallanch J. Introduction to 3D imaging technologies for the facial plastic surgeon. Facial Plast Surg Clin North Am. 2011 Nov;19(4):xv-xvi, vii. doi: 10.1016/j. fsc. 2011.07.001.

11.Donath AS, Glasgold RA, Meier J, Glasgold MJ. Quantitative evaluation of volume augmentation in the tear trough with a hyaluronic Acid-based filler: a threedimensional analysis. Plast Reconstr Surg. 2010 May;125(5):1515-22. doi: 10.1097/ PRS.0b013e3181d70317.

12. Nikkhah D, Ponniah A, Ruff C, Dunaway D. Planning surgical reconstruction in treachercollins syndrome using virtual simulation. Plast Reconstr Surg. 2013;132(5):790e-805e. doi: 10.1097/PRS.0b013e3182a48d33.

13.Ji Y, Zhang F, Schwartz J, Stile F, Lineaweaver WC. Assessment of facial tissue expansion with three-dimensional digitizer scanning. J Craniomaxillofac Surg. 2002;13(5):687-92. doi: $\quad 10.1097 / 01 . S C S .0000026451 .58930$. C2.

14. Hermans DJ, Maal TJ, Berge SJ, van der Vleuten CJ. Three-dimensional stereophotogrammetry: a novel method in volumetric measurement of infantile hemangioma. Pediatr Dermatol. 2014 JanFeb;31(1):118-22. doi: 10.1111/pde.12224.

15.Small KH, Choi M, Levovitz C, Lee C, Karp $\mathrm{N}$. Fat graft survival in the radiated breast compared to non-radiated breast: volume measurement using 3D imaging. Plast Reconst Surg. 2012;130(5S-1):86.

16.Jayaratne YS, Lo J, Zwahlen RA, Cheung LK. Three-dimensional photogrammetry for surgical planning of tissue expansion in hemifacial microsomia. Head Neck. 2010 Dec;32(12):1728-35. doi: 10.1002/ hed. 21258.

17.Lee J, Kawale $M$, Merchant FA, Weston J, Fingeret MC, Ladewig D, Reece GP, Crosby MA, Beahm EK, Markey MK. Validation of stereophotogrammetry of the human torso. Breast Cancer. 2011;5:15-25. doi: 10.4137/ BCBCR.S6352. 
18.Weinberg SM, Scott NM, Neiswanger K, Brandon CA, Marazita ML. Digital threedimensional photogrammetry: evaluation of anthropometric precision and accuracy using a Genex 3D Camera System. Cleft Palate J. 2004;41(5):507-18.

19.Winder RJ, Darvann TA, McKnight W, Magee JD, Ramsay-Baggs P. Technical validation of the Di3D stereophotogrammetry surface imaging system. Br J Oral Maxillofac Surg. 2008 Jan;46(1):33-7. doi: 10.1016/j. bjoms.2007.09.005.

20.Tzou $\mathrm{CH}$, Frey M. Evolution of 3D surface imaging systems in facial plastic surgery. Facial Plast Surg Clin North Am. 2011 Nov;19(4):591-602, vii. doi: 10.1016/j. fsc.2011.07.003.

21.Khambay B, Nairn N, Bell A, Miller J, Bowman A, Ayoub AF. Validation and reproducibility of a high-resolution three-dimensional facial imaging system. Br J Oral Maxillofac Surg. 2008 Jan;46(1):27-32. doi: 10.1016/j. bjoms.2007.04.017.

22.Russell JH, Kiddy HC, Mercer NS. The use of SymNose for quantitative assessment of lip symmetry following repair of complete bilateral cleft lip and palate. J Craniomaxillofac Surg. 2014 Jul;42(5):454-9. doi: 10.1016/j.jcms.2013.05.041.

23.Fink M, Medelnik J, Strobel K, Hirschfelder U, Hofmann E. Metric precision via soft-tissue landmarks in three-dimensional structuredlight scans of human faces. J Orofac Orthop. 2014 march 02;75:133-43. doi: 10.1007/ s00056-013-0201-9.

24.Stančić I, Musić J, Zanchi V. Improved structured light 3D scanner with application to anthropometric parameter estimation. Measurement. 2013;46(1):716-26. doi: 10.1016/j.measurement.2012.09.010.

25.Pyka M, Klatt S, Cheng S. Parametric anatomical modeling: a method for modeling the anatomical layout of neurons and their projections. Front Neuroanat. 2014;8:91. doi: 10.3389/fnana.2014.00091.

26.Pyka M, Hertog M, Fernandez R, Hauke S, Heider D, Dannlowski U, Konrad C. fMRI data visualization with BrainBlend and Blender. Neuroinformatics. 2010 Mar;8(1):21-31. doi: 10.1007/s12021-009-9060-3.

27.Guest E, Berry E, Morris D. Novel methods for quantifying soft tissue changes after orthognathic surgery. Int J Oral Maxillofac
Surg. 2001 Dec;30(6):484-9. doi: 10.1054/ ijom.2001.0173.

28.Lin SJ, Patel N, O'Shaughnessy K, Fine NA. Three-dimensional imaging in measuring facial aesthetic outcomes. Laryngoscope. 2008 Oct;118(10):1733-8. doi: 10.1097/ MLG.0b013e31817e245c.

29.Stern CS, Schereiber JE, Surek CC, Garfein ES, Jelks EB, Jelks GW, Tepper OM. Threedimensional topographic surface changes in response to compartmental volumization of the medial cheek: defining a malar augmentation zone. Plast Reconst Surg. 2016 May 2016;137(5):1401-7. doi: 10.1097/PRS.0000000000002066.

30.Benn P, Ruff C, Cartledge J, Sauret V, Copas A, Linney A, Williams IG, Smith CJ, Edwards SG. Overcoming subjectivity in assessing facial lipoatrophy: is there a role for threedimensional laser sacans? HIV Med. 2003;4:325-31.

31. Herlin C, Subsol G, Gilles B, Captier G, Chaput $B$. Three-dimensional surface imaging is not enough for surgical simulation. Plast Reconstr Surg. 2016 Jan;137(1):246e-7e. doi: 10.1097/PRS.0000000000001921.

32.Pedersen A, Maersk-Moller O. Volumetric determination of extraoral swelling from stereophotographs. Int J Oral Surg. 1985;14:229-34.

33. Hajeer MY, Mao Z, Millett DT, Ayoub AF, Siebert JP, Ceng. A new three-dimensional method of assessing facial volumetric changes after orthognathic treatment. Cleft Palate Craniofac J. 2004;42(2):113-20.

34.Park $\mathrm{H}$, Chung J, Khon $\mathrm{H}$. Use of handheld laser scanning in the assessment of craniometry. Forensic Sci. 2006;160:200-6. doi: 10.1016/j.forsciint.2005.10.007.

35.Hsu VM, Wes AM, Tahiri Y, CornmanHomonoff J, Percec I. Quantified facial soft-tissue strain in animation measured by real-time dynamic 3-dimensional imaging. Plast Reconstr Surg Glob Open. 2014 Oct 7;2(9):e211. doi: 10.1097/ GOX.0000000000000185.

36.Iblher N, Gladilin E, Stark BG. Soft-tissue mobility of the lower face depending on positional changes and age: a threedimensional morphometric surface analysis. Plast Reconst Surg. 2013;131(2):372-81. doi: 10.1097/PRS.0b013e318278d67c.

37.Nkenke E, Vairaktaris E, Kramer M, Schlegel 
A, Holst A, Hirschfelder U, Wiltfang J, Neukam FW, Stamminger $M$. Three-dimensional analysis of changes of the malar-midfacial region after LeFort I osteotomy and maxillary advancement. Oral Maxillofac Surg. 2008 May;12(1):5-12. doi: 10.1007/s10006-0080094-8.

38.Winzweig J, Oliker A, Cutting CB, Aston SJ, Smith DM. Designing a virtual reality model for aesthetic surgery. Plast Reconst Surg. 2004 September 1;116(3):893-7. doi: 10.1097/01.prs.0000176900.62853.b3.

39.Alfano C, Mezzana P, Scuderi N. Acquisition and elaboration of superficial threedimensional images in plastic and reconstructive surgery: aplications. Indian J Plast Surg. 2005 january-june;38(1):22-7.

40.Dornelles RDFV, Alonso N, Tissiani LAL, Souza AR, Cardim VLN. The use of a threedimensional mesh in plastic surgery. Rev Bras Cir Plást. 2016;31(1):25-31. doi: 10.5935/2177-1235.2016rbcp0005.

41.Wong JY, Oh AK, Ohta E, Hunt AT, Rogers GF, Mulliken JB, Deutsch CK. Validity and reliability of craniofacial anthropometric measurement of 3D digital photogrammetric images. Cleft Palate Craniofac J. 2007;45(3):232-9. doi: 10.1597/06-175.1.

42.Paul SM, Chamberlin AP, Hatt C, Nayak AV, Danoff J. Reliability, validity, and precision of an active stereophotogrammetry system for three-dimensional evaluation of the human torso. Med Eng Phys. 2009;31(10):1337-42. doi: 10.1016/j.medengphy.2009.08.011.

43. Henseler H, Khambay BS, Bowman A, Smith
J, Paul Siebert J, Oehler S, Ju X, Ayoub A, Ray AK. Investigation into accuracy and reproducibility of a 3D breast imaging system using multiple stereo cameras. J Plast Reconstr Aesthet Surg. 2011 May;64(5):57782. doi: 10.1016/j.bjps.2010.08.044.

44.van der Vlis $M$, Dentino KM, Vervloet $B$, Padwa BL. Postoperative swelling after orthognathic surgery: a prospective volumetric analysis. J Oral Maxillofac Surg. 2014 Nov;72(11):2241-7. doi: 10.1016/j. joms.2014.04.026.

45.Koh KS, Oh TS, Kim H, Chung IW, Lee KW, Lee HB, Park EJ, Jung JS, Shin IS, Ra JC, Choi JW. Clinical application of human adipose tissue-derived mesenchymal stem cells in progressive hemifacial atrophy (ParryRomberg disease) with microfat grafting techniques using 3-dimensional computed tomography and 3-dimensional camera. Ann Plast Surg. 2012;69(3):331-7. doi: 10.1097/SAP.0b013e31826239f0.

46.Tanikawa DY, Aguena M, Bueno DF, Passos-Bueno MR, Alonso N. Fat grafts supplemented with adipose-derived stromal cells in the rehabilitation of patients with craniofacial microsomia. Plast Reconstr Surg. 2013 Jul;132(1):141-52. doi: 10.1097/ PRS.0b013e3182910a82.

\section{Acknowledgement}

To Professor Cícero Moraes for the vital guidance of the graphic designer.

\section{Correspondence:}

Rodrigo de Faria Valle Dornelles

Rua Doutor Barros Cruz, 172 / casa 18

04118-130 São Paulo - SP Brasil

rodrigodornelles@gmail.com

Received: Aug 17, 2017

Review: Oct 18, 2017

Accepted: Nov 16, 2017
Conflict of interest: none

Financial source: CAPES

\footnotetext{
${ }^{1}$ Research performed at Division of Plastic Surgery, Department of Surgery, Universidade de São Paulo (USP), Brazil. Part of PhD degree thesis, Postgraduate Program in Science. Tutor: Nivaldo Alonso.
} 